\title{
PREPARAÇÃO E CARACTERIZAÇÃO DE ARGILA ORGANOFÍlLICA PARA REMOÇÃO DE TOLUENO
}

\author{
M.F. OLIVEIRA ${ }^{1}$; S. BEDIN²; M.G.A. VIEIRA ${ }^{3}$, O.A. ANDREO dos SANTOS ${ }^{4}$ E M.G.C. \\ da SILVA ${ }^{3}$
}

(1) Bolsista de Iniciação Científica - CNPq; (2) Mestranda - LEA/DDPP/FEQ/UNICAMP; (3) Docente - DDPP/FEQ/UNICAMP; (4) Docente - DEQ/UEM

Departamento de Desenvolvimento de Processos e Produtos - Faculdade de Engenharia Química - UNICAMP, Av. Albert Einstein, 500 - Campinas, SP - CEP 13083-852 - e-mail: meuris@feq.unicamp.br

\begin{abstract}
RESUMO - Argilas organofílicas possuem grande afinidade por compostos orgânicos. Desta forma, estão sendo aplicadas na adsorção e retenção de resíduos industriais perigosos e contaminantes orgânicos. Neste trabalho preparou-se a argila organofílica a partir de trocas iônicas entre a argila comercial Fluidgel e o sal brometo de hexadeciltrimetilamônio (HDTMA). As argilas, comercial e organofílica foram caracterizadas por medidas de adsorção-dessorção de $\mathrm{N}_{2}$, difração de raios $\mathrm{X}$ e análise termogravimétrica. Para a argila organofílica, também foram realizados ensaios de hidratação e testes de expansão de Foster em água e na presença de benzeno, tolueno e xileno. Foram conduzidos de adsorção em banho utilizando-se as argilas comercial e organofílica. Os resultados obtidos com as caracterizações comprovaram a ocorrência do processo de organofilização. Os ensaios cinéticos possibilitaram a observação do potencial de remoção do tolueno em solução aquosa utilizando a argila modificada com HDTMA como material adsorvente.
\end{abstract}

\section{INTRODUÇÃO}

A necessidade de encontrar tecnologias eficientes e economicamente viáveis de remoção de poluentes da água aumenta a cada dia. Compostos conhecidos como BTX (benzeno, tolueno e xileno) fazem parte da constituição de derivados de petróleo e são altamente tóxicos ao meio ambiente e aos seres vivos. Esses poluentes são muitas vezes descartados em água limpa por indústrias que durante seus processos de produção, têm a necessidade de lavar seus produtos.

Sistemas de purificação envolvendo argilas organofílicas têm sido utilizados com sucesso na separação de compostos orgânicos da água (Bertagnolli, 2010). As argilas possuem natureza hidrofílica e naturalmente não apresentam grande potencial para remoção de compostos orgânicos de água. Por isso, há a necessidade de tratar a argila com compostos orgânicos adequados para que esta adquira caráter organofílico. (Silva e Ferreira, 2008). Se submetidas a tratamentos químicos com sais quaternários de amônio, a superfície da argila é alterada e passa a apresentar caráter hidrofóbico e organofílico. Essa descoberta permitiu que argilas modificadas pudessem ser amplamente utilizadas em estudos de adsorção de 
resíduos industriais orgânicos tóxicos, como por exemplo, os compostos BTX (Bertagnolli, 2010).

As argilas esmectíticas, abundantes na natureza, possuem cristais pequenos e grande capacidade de troca catiônica, o que torna seu uso extremamente favorável na síntese de argilas organofílicas (Santos, 1992). Desta forma, o presente trabalho teve por objetivo preparar e caracterizar argilas organofílicas para posterior aplicação no tratamento de águas contendo tolueno.

\section{MATERIAIS E MÉTODOS}

\subsection{Preparação do adsorvente modificado}

A argila modificada (argila organofílica) foi preparada a partir da reação entre a argila Fluidgel Comercial, do tipo bentonítica sódica ativada, fornecida por Dolomil Industrial LTDA e o sal quaternário de amônio, o brometo de hexadeciltrimetilamônio (HDTMA), conforme a metodologia descrita por Bedin et al. (2013). A argila preparada foi triturada e peneirada para que se obtivessem partículas com diâmetro médio de $0,855 \mathrm{~mm}$ e de 0,55 $\mathrm{mm}$. Esse material foi utilizado na caracterização e nos ensaios de adsorção.

\subsection{Caracterização dos adsorventes}

Os testes de caracterização foram realizados para a argila comercial e para a argila modificada. Todos os processos realizados seguiram a metodologia descrita por Andreo dos Santos e Silva (2012).

$\mathrm{Na}$ análise de cristalinidade foi utilizada difração de raios $\mathrm{X}$, utilizando o método de varredura. Foram determinados os espaçamentos basais em função das mudanças na

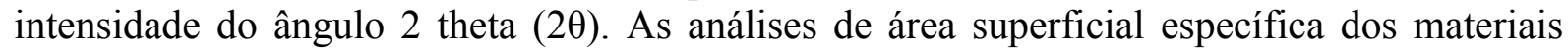
adsorventes, o volume total de poros ( $\mathrm{Vp}$ ), diâmetro médio de poros (dp) e isotermas de adsorção, foram realizadas a partir de medidas de adsorção-dessorção de $\mathrm{N}_{2}$. A área superficial específica $(\mathrm{Sg})$ de cada tipo de argila foi calculada usando o método BET (Brunauer, Emmett e Teller) e os parâmetros de poros foram determinados com base nos cálculos BJH (Barrett-Joyner-Halenda).

Para determinar a estabilidade térmica, quantidade de água e a pureza das argilas, comercial e organofílica, bem como para acompanhar as transformações que estes materiais sofrem durante o aquecimento foram realizadas análises termogravimétricas (TG/DTG) e calorimetria exploratória diferencial (DSC). Por sua vez, foram realizados ensaios de hidratação, para determinar o comportamento das argilas na presença de água e ensaios de expansão em meio orgânico (expansão de Foster), para determinar o comportamento das argilas na presença de BTX, segundo a metodologia proposta por Díaz (1994) e Foster (1953).

\subsection{Estudo cinético}

As curvas das cinéticas de adsorção foram obtidas utilizando cromatografia líquida de alta eficiência (HPLC) com coluna C18 e fase móvel de $28 \%$ de acetonitrila, $35 \%$ de metanol e $37 \%$ de água mili-Q. Os ensaios foram realizados com a argila comercial e a organofílica. 
Nestes ensaios, 2,5 g de argila com diâmetro de partícula de $0,55 \mathrm{~mm}$ foram adicionados em um erlenmeyer contendo $250 \mathrm{~mL}$ de solução aquosa de tolueno, na concentração inicial de 1 $\mathrm{mmol} / \mathrm{L}$, em $\mathrm{pH}$ inicial de aproximadamente 10, que não foi ajustado durante o ensaio. Alíquotas foram coletadas em tempos pré-estabelecidos, filtradas em membranas Miliq (filtro millex) e analisadas no HPLC para que se determinar a concentração final de tolueno na solução, a partir da curva calibração previamente determinada.

\section{RESULTADOS E DISCUSSÃO}

\subsection{Caracterização dos adsorventes}

Os resultados obtidos pelas análises de DRX, Tabela 1, mostram que o HDTMA promove a modificação na estrutura da argila com a antecipação do ângulo $2 \theta$, de 6,92 na argila comercial para 4,29 na argila organofílica, e, consequentemente, um aumento na distância basal, de acordo com a Lei de Bragg, de $13 \AA$ para $21 \AA$, após o processo de organofilização. Essa mudança na estrutura da argila obtida após o tratamento com HDTMA evidencia a intercalação efetiva dos cátions do sal nas camadas interlamelares, os seja, a troca ocorrida entre os íons sódio e os cátions provenientes do HDTMA aumenta o espaçamento entre as camadas da argila (Andreo dos Santos e Silva, 2012; Almeida Neto, 2011).

Tabela 1- Distância interplanar das Argilas obtidas em análise de DRX

\begin{tabular}{ccc}
\hline Argila & Ângulo correspondente $(2 \theta)$ & Distância interplanar basal $(\AA)$ \\
\hline Organofílica & 4,29 & 20,58 \\
\hline Comercial & 6,92 & 12,76 \\
\hline
\end{tabular}

A análise da estrutura porosa, cujos resultados encontram-se na Tabela 2, permitiu verificar que ocorreu modificação na estrutura da argila Fluidgel comercial após o processo de organofilização. De acordo com os resultados obtidos observa-se uma redução significativa da área superficial específica e, consequentemente a redução do volume específico de poros e do diâmetro médio de poros, como verificado por Andreo dos Santos e Silva (2012). Para a argila Fluidgel comercial os valores obtidos para a área superficial específica, volume específico de poros e diâmetro médio de poros foram de $60 \mathrm{~m}^{2} / \mathrm{g}, 0,086 \mathrm{~cm}^{3} / \mathrm{g}$ e $40 \AA$, enquanto que para a argila organofílica os valores obtidos foram de $6 \mathrm{~m}^{2} / \mathrm{g}, 0,013 \mathrm{~cm}^{3} / \mathrm{g}$ e $27 \AA$, respectivamente. Essa mudança pode ser atribuída à intercalação dos cátions orgânicos do HDTMA na microestrutura da argila, conforme observado nas análises de difração de raios X, dificultando a passagem das moléculas de $\mathrm{N}_{2}$ e ocupando sítios que seriam ocupados por estas (Lee et al., 1989). As isotermas de adsorção-dessorção das amostras de argilas podem ser classificadas, segundo a IUPAC (1985), isotermas do tipo IV, características de adsorção multicamadas com mudança de nível a pressões relativamente altas, implicando na presença de mesoporos.

Tabela 2- Parâmetros texturais das argilas comercial e organofílica.

\begin{tabular}{cccc}
\hline Argila & $\mathrm{Sg}\left(\mathrm{m}^{2} / \mathrm{g}\right)$ & $\mathrm{Vp}\left(\mathrm{cm}^{3} / \mathrm{g}\right)$ & $\mathrm{dp}(\AA)$ \\
\hline Organofílica & 6,23 & 0,013 & 26,64 \\
\hline Comercial & 59,87 & 0,086 & 40,17 \\
\hline
\end{tabular}


$\mathrm{Na}$ análise termogravimétrica das argilas, Figura 1, foi possível verificar a eliminação de água para ambas as argilas onde são observadas regiões de perda de massa entre $25{ }^{\circ} \mathrm{C}$ e $150^{\circ} \mathrm{C}$. Segundo Andreo dos Santos e Silva (2012), o pico de perda de água para a argila organofílica é menor do que o pico para a argila comercial porque a matéria orgânica adsorvida altera as ligações entre a estrutura da argila e a água, fazendo com que o pico de desidratação apareça em temperaturas mais baixas e com menor intensidade. Para a argila organofílica, observa-se o surgimento de um pico de perda de massa entre 150 e $550{ }^{\circ} \mathrm{C}$, atribuído à combustão da parte orgânica proveniente do sal quaternário de amônio. As análises de DSC também indicaram modificações na estrutura da argila após a reação com o sal quaternário de amônio. Foram observadas três regiões de variação de entalpia para as argilas organofílicas, a primeira (para temperaturas abaixo dos $200{ }^{\circ} \mathrm{C}$ ) pode ser atribuída à desidratação com picos endotérmicos (água externa ou interlamelar), a segunda às reações térmicas da matéria orgânica com picos endotérmicos característicos da evaporação e decomposição dos compostos orgânicos proveniente do sal quaternário de amônio (para temperaturas acima de $200{ }^{\circ} \mathrm{C}$ ), e a terceira e referente à desidroxilação da argila organofílica, também com picos endotérmicos (Andreo dos Santos e Silva, 2012).

Figura 1- Análise Termogravimétrica das argilas

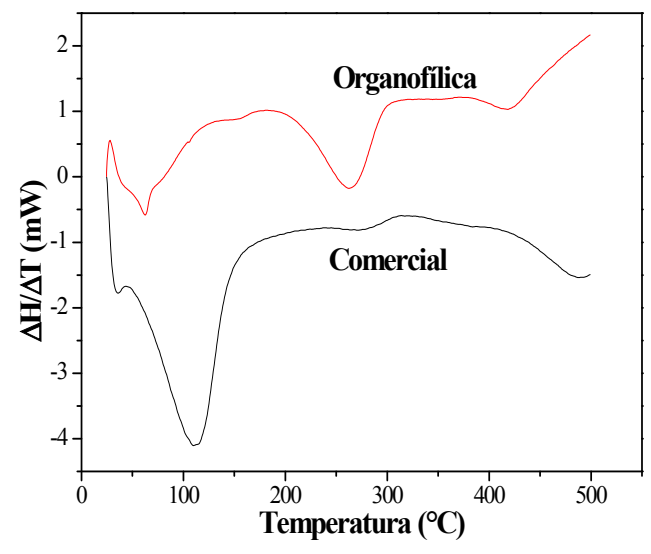

Os ensaios da capacidade de hidratação das argilas mostraram que a argila comercial sofreu expansão em meio aquoso e a argila organofílica apresentou separação dinâmica entre o material adsorvente e a água. Esse fato reforça o caráter hidrofóbico que a mesma adquiriu durante a sua modificação com o sal quaternário de amônio. O caráter organofílico da argila modificada ficou evidenciado nos ensaios de expansão. Em contato com substâncias do grupo BTX por um período de 48 horas, observou-se que a argila modificada com HDTMA se expandiu, conforme descrito por Andreo dos Santos e Silva (2012).

\subsection{Estudo cinético}

A cinética de adsorção do tolueno na superfície das argilas Fluidgel comercial e organofílica, na concentração inicial de $1 \mathrm{mmol} / \mathrm{L}$ e temperatura ambiente, bem como os ajustes dos modelos cinéticos de pseudoprimeira ordem e pseudossegunda ordem para as argilas, comercial e organofílica, estão apresentados nas Figuras 2a e 2b. Na Tabela 3 encontram-se os parâmetros desses ajustes. 
Figura 2- Comportamento cinético da adsorção de tolueno e modelos de pseudoprimeira ordem e pseudossegunda ordem para: a) argila comercial: b) argila organofílica.
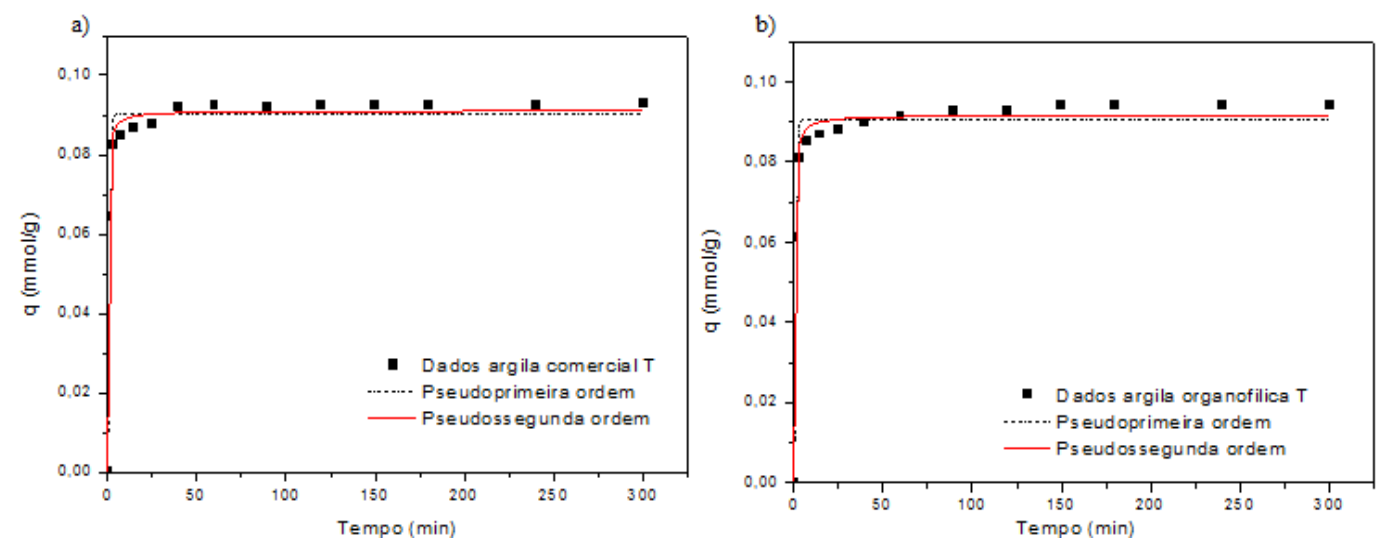

Observa-se pelas Figuras $2 \mathrm{a}$ e $2 \mathrm{~b}$ que a adsorção do tolueno aumentou rapidamente durante os primeiros 60 minutos, e no tempo restante a adsorção aumentou de maneira moderada, o que segundo Nourmoradi et al. (2012) indica a redução de inúmeros sítios adsortivos do início do processo. O equilíbrio foi atingido em aproximadamente 90 minutos para ambas as argilas, considerando uma porcentagem de remoção de $96 \%$. Contudo, para a argila comercial observou-se a formação de um gel quando em contato com o tolueno, o que pode dificultar a sua aplicação em sistemas dinâmicos de leito fixo (Bedin et al., 2013). As cinéticas de adsorção do tolueno, tanto para a argila comercial quanto para a argila organofílica tiveram melhor ajuste pelo modelo de pseudossegunda ordem, o que fica evidenciado pelos parâmetros ajustáveis apresentados na Tabela 3. Embora a argila comercial tenha sido organofilizada, a capacidade adsortiva deste adsorbato pela mesma não variou.

Tabela 3- Parâmetros dos ajustes para tolueno: pseudoprimeira ordem e pseudossegunda ordem

\begin{tabular}{ccccccc}
\hline \multirow{2}{*}{ Argila } & \multicolumn{3}{c}{ Pseudoprimeira Ordem } & \multicolumn{3}{c}{ Pseudossegunda Ordem } \\
\cline { 2 - 7 } & $\begin{array}{c}q_{e} \\
(\mathrm{mmol} / \mathrm{g})\end{array}$ & $\begin{array}{c}K_{1} \\
(\mathrm{~g} / \mathrm{mmol})\end{array}$ & $\mathrm{R}^{2}$ & $\begin{array}{c}q_{e} \\
(\mathrm{mmol} / \mathrm{g})\end{array}$ & $\begin{array}{c}K_{2} \\
(\mathrm{~g} / \mathrm{mmol})\end{array}$ & $\mathrm{R}^{2}$ \\
\hline Organofílica & 0,09041 & 2,25010 & 0,97279 & 0,09170 & 3,60875 & 0,98822 \\
\hline Comercial & 0,09004 & 2,51835 & 0,98046 & 0,09108 & 4,47433 & 0,99129 \\
\hline
\end{tabular}

\section{CONCLUSÕES}

A modificação química da argila Fluidgel comercial com HDTMA foi satisfatória e, alterou o seu caráter naturalmente hidrofílico para hidrofóbico e organofílico, o que foi conformado com o aumento do espaçamento basal e pelo surgimento de uma etapa adicional de perda de massa durante as análises térmicas. As técnicas de caracterização confirmaram, portanto, a ocorrência da organofilização da argila comercial após o tratamento com HDTMA, o que foi ilustrado pelos testes de compatibilidade e afinidade. O equilíbrio cinético foi atingido aos 90 minutos com $96 \%$ de adsorção. O modelo cinético de pseudossegunda ordem foi o que melhor se ajustou aos dados obtidos, indicando que o adsorbato ocupa o adsorvente por dois sítios ativos (Blanchard et al., 1984). 


\section{REFERÊNCIAS}

ANDREO dos SANTOS, O. A., e da SILVA, M. G. C.; Preparação e Caracterização De Argilas Fluidgel Organofilicas. Congresso Brasileiro e Engenharia Química, 2012.

BEDIN S., OLIVEIRA M. F., VIEIRA M. G. A., ANDREO DOS SANTOS O. A., SILVA M. C. G.; Adsorption of Toluene in Batch System in Natural Clay and Organoclay. Chemical Engineering Transactions, v. 32, p. 1-6, 2013.

BERTAGNOLLI, C.; Preparo e caracterização de argilas organofilicas para remoção de derivados de petróleo. Dissertação (Mestrado), Campinas: UNICAMP, 2010.

BLANCHARD, G., MAUNAYE, M., MARTIM, G.; Removal of heavy metals from waters by means of natural zeolites. Water Research. 18, 1501-1507, 1984.

DÍAZ, F. R. V., Preparação em nível de laboratório de algumas argilas esmectíticas organofilicas. Tese de Doutorado. São Paulo: EPUSP, 1994.

FOSTER, M. D.; Geochemical studies of clay minerals: II-relation between ionic substitution and swelling in montmorillonites. Geochimica et Cosmochimica Acta, v. 3, n. 2-3, p. 143-154, 1953.

IUPAC Recommendations. Pure Appl. Chem., v. 57, p. 603, 1985.

LEE, J.-F.; MORTLAND, M. M.; BOYD, S. A.; CHIOU, C. T.; Shape-selective adsorption of aromatic molecules from water by tetramethylammonium-smectite. Journal of the Chemical Society, Faraday Transactions 1: Physical Chemistry in Condensed Phases, v. 85, n. 9, p. 2953-2962, 1989.

NOURMORADI H., NIKAEEN M., HAJIAN M. K.; Removal of benzene, toluene, ethylbenzene and xylene (BTEX) from aqueous solutions by montmorillonite modified with nonionic surfactant: Equilibrium, kinetic and thermodynamic study.Chemical Engineering Journal, v. 191, p. 341-348, 2012.

SANTOS, P. de S. Ciência e tecnologia de argilas. 2. ed. Sao Paulo: Edgard Blucher Ltda., 408 p., v.2, 1992.

SILVA, A. R. V.; FERREIRA, H. C.; Esmectitas organofilicas: conceitos, estruturas, propriedades, sintese, usos industriais e produtores/fornecedores nacionais $e$ internacionais. Revista eletrônica de Materiais e Processos, v. 3.3, p. 01-11, 2008.

\section{AGRADECIMENTOS}

Ao programa PIBIC/CNPQ pela concessão da Bolsa de Iniciação Científica e à FAPESP e ao CNPq pelo suporte financeiro. 